\title{
SEASONAL PARAMETERIZATIONS OF THE TAU-OMEGA MODEL USING THE COMRAD GROUND-BASED SMAP SIMULATOR
}

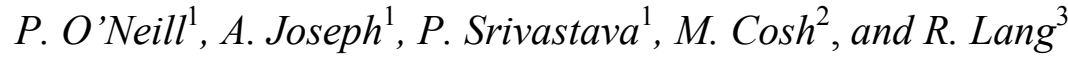 \\ ${ }^{1}$ Hydrological Sciences Laboratory / Code 617 \\ NASA Goddard Space Flight Center, Greenbelt, MD 20771 USA \\ tel: 1-301-614-5773, fax: 1-301-614-5808, Peggy.E.ONeill@nasa.gov \\ ${ }^{2}$ Hydrology and Remote Sensing Laboratory, U.S. Dept. of Agriculture/Agricultural Research Service* \\ Beltsville, MD 20105 USA \\ ${ }^{3}$ Dept. of Electrical \& Computer Engineering, George Washington University \\ Washington, DC 20052 USA
}

\begin{abstract}
NASA's Soil Moisture Active Passive (SMAP) mission is scheduled for launch in November 2014. In the prelaunch time frame, the SMAP team has focused on improving retrieval algorithms for the various SMAP baseline data products. The SMAP passive-only soil moisture product depends on accurate parameterization of the tau-omega model to achieve the required accuracy in soil moisture retrieval. During a field experiment (APEX12) conducted in the summer of 2012 under dry conditions in Maryland, the ComRAD truck-based SMAP simulator collected active/passive microwave time series data at the SMAP incident angle of $40^{\circ}$ over corn and soybeans throughout the crop growth cycle. A similar experiment was conducted only over corn in 2002 under normal moist conditions. Data from these two experiments will be analyzed and compared to evaluate how changes in vegetation conditions throughout the growing season in both a drought and normal year can affect parameterizations in the tau-omega model for more accurate soil moisture retrieval.
\end{abstract}

Keywords (Index Terms) -- soil moisture, microwave, tau-omega model, ComRAD, SMAP, seasonal parameterization.

\section{INTRODUCTION}

Soil moisture is a critical variable in land surface hydrology, and large-scale mapping of soil

$\overline{\text { *USDA and NASA are equal opportunity employers. }}$ moisture based on microwave remote sensing will enable new science and applications of benefit to society. NASA's upcoming SMAP (Soil Moisture Active Passive) mission, currently scheduled for launch in November 2014, will provide global mapping of soil moisture and freeze/thaw state every 2-3 days using data from an L-band radiometer (40 $\mathrm{km}$ resolution) and/or an L-band radar (3 $\mathrm{km}$ resolution) [1]. SMAP will continue the legacy of soil moisture measurements produced by ESA's ongoing L-band SMOS (Soil Moisture Ocean Salinity) mission. Although differing in the details of their algorithm approaches, passive-only soil moisture retrievals from both SMOS and SMAP are fundamentally based on the same tau-omega model [2,3]. When used for soil moisture retrieval, the tau-omega model requires parameterization of the effects of the overlying vegetation canopy. These parameterizations have traditionally been developed for peak biomass conditions at a single polarization - the polarization and seasonal variations in the vegetation parameterizations are often ignored. Refinement of these parameterizations for use in year-round soil moisture retrieval from space requires L-band data sets in time series over a long enough time period to reflect changing surface conditions (vegetation, soil moisture, etc.). As part of SMAP algorithm development activities, NASA GSFC's ComRAD 
truck-mounted microwave instrument system collected L-band active/passive data throughout the growing season over corn and soybean crops from June 1 through October 24, 2012, along with associated ground truth and vegetation characterization data. These data, along with time series data from a similar 2002 experiment in the same location, will be used to assess the magnitude of the possible seasonal and polarization variations in the tau-omega vegetation parameterizations, especially as compared to a constant parameterization for a given vegetation type where changes in the vegetation water content alone account for any time dependence in the soil moisture retrieval algorithms.

\section{TAU-OMEGA MODEL}

Retrieval of soil moisture from surface brightness temperature $\left(T_{B}\right)$ observations is based on a well-known zero-order approximation to the radiative transfer equation, commonly known as the tau-omega model. A layer of vegetation over a soil attenuates the emission of the soil and adds to the total radiative flux with its own emission. Assuming that scattering within the vegetation is negligible at $\mathrm{L}$ band frequencies, the vegetation may be treated mainly as an absorbing layer. A model following this approach to describe the brightness temperature of a weakly scattering layer above a semi-infinite medium is shown below and includes emission components from the soil and the overlying vegetation canopy:

$$
\begin{array}{r}
T_{B p}=T_{s} e_{p} \exp \left(-\tau_{p} \sec \theta\right)+T_{v}\left(1-\omega_{p}\right)[1- \\
\left.\exp \left(-\tau_{p} \sec \theta\right)\right]\left[1+r_{p} \exp \left(-\tau_{p} \sec \theta\right)\right]
\end{array}
$$

where the subscript $p$ refers to polarization ( $V$ or $H), T_{s}$ is the soil effective temperature, $T_{v}$ is the vegetation temperature, $\tau_{p}$ is the nadir vegetation opacity, $\omega_{p}$ is the vegetation single scattering albedo, and $r_{p}$ is the rough soil reflectivity. The reflectivity is related to the emissivity $\left(e_{p}\right)$ by $e_{p}=$ $\left(1-r_{p}\right)$, and $\omega_{p}, r_{p}$ and $e_{p}$ are values at the SMAP look angle of $\theta=40^{\circ}$. The transmissivity $\gamma$ of the overlying canopy layer is $\gamma=\exp \left(-\tau_{p} \sec \theta\right)$. Equation (1) assumes that vegetation multiple scattering and reflection at the vegetation-air interface are negligible. Nadir vegetation opacity is related to the total columnar vegetation water content (VWC, in $\mathrm{kg} / \mathrm{m}^{2}$ ) by $\tau_{p}=b_{p}{ }^{*} V W C$ with the coefficient $b_{p}$ dependent on vegetation type and microwave frequency (and probably polarization) [4]. For L-band missions, the coefficient $b_{p}$ is often taken to be constant for any given vegetation type, such that any variations in tau $\tau_{p}$ throughout the year are caused solely by variations in VWC.

\section{2002 AND 2012 FIELD EXPERIMENTS}

Extensive field experiments from crop planting through senescence were conducted in both 2002 and 2012 at the heavily instrumented USDA-ARS (U.S. Dept. of Agriculture-Agricultural Research Service) OPE3 [5] test site in Beltsville, MD to acquire data needed to address active/passive microwave algorithm needs for accurate soil moisture retrieval $[6,7]$. Vegetation cover in the 2002 experiment consisted of a corn crop, while both corn and soybeans were measured in the 2012 experiment. 2002 was a normal year in terms of crop growth, while in 2012 the local Maryland test site area experienced drought conditions in June and July which significantly stunted the growth of the corn canopy (Fig. 1a). In 2012 in situ soil moisture, soil temperature, and leaf wetness sensors were installed by USDA to provide continuous ground truth data. These data were supplemented by additional soil moisture data collected manually twice a week by USDA personnel, along with weekly plant architectural, biomass/water content, and density measurements. The OPE3 site also contains a SCAN meteorological station and a flux tower which record precipitation and other micrometeorological data. ComRAD microwave measurements were made at the SMAP incidence angle of $40^{\circ}$ in 2012 (Fig. 1b) and at $35^{\circ}$ in 2002.

\section{ANALYSIS}

Figure 2 shows the measured vegetation water content (by plant constituent) for the corn canopies in 2012 (Fig. 2a) and 2002 (Fig. 2b). 


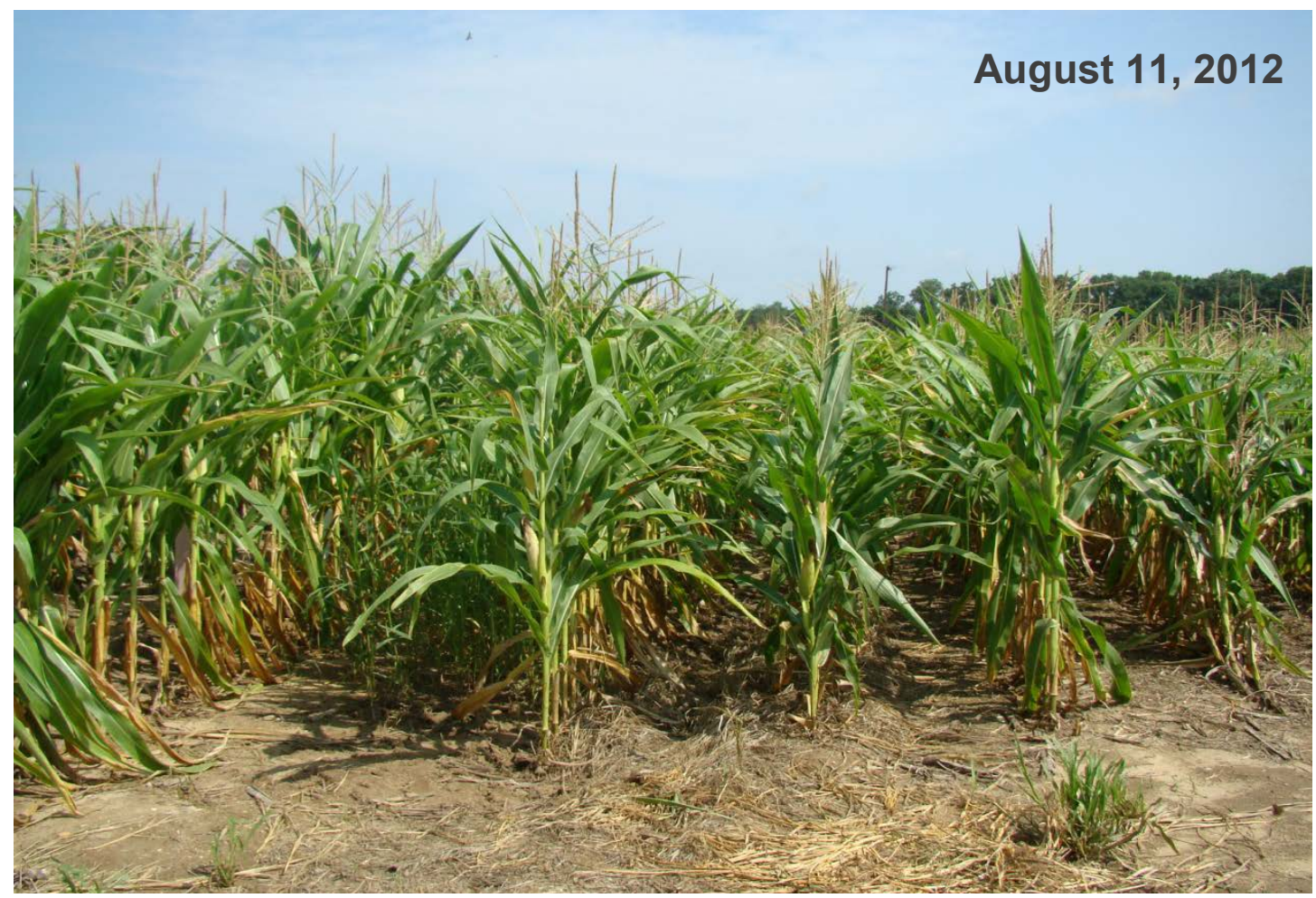

(a)

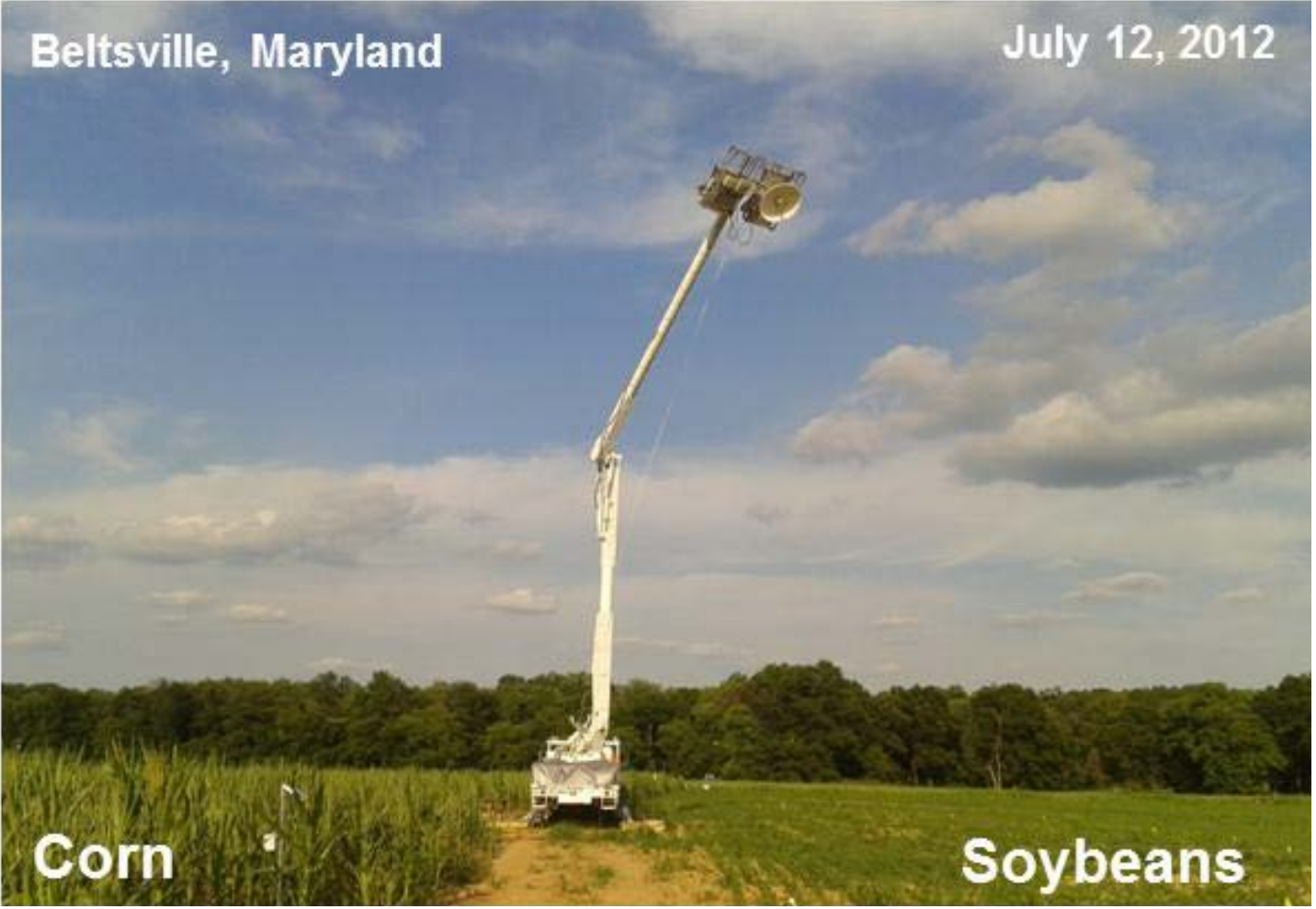

(b)

Figure 1. (a) Corn canopy on August 11, 2012 showing stunted growth due to drought conditions in June and July; (b) ComRAD truck-mounted instrument system deployed at the USDA OPE3 test site. 
Note the similarity of the shape of the curves despite the difference in biomass between the two years. Using the vegetation biomass, geometry, and dielectric data collected during the experiments, a discrete vegetation scattering model [8] is used to produce estimates of microwave attenuation through the corn canopies for 2002 and 2012. These estimates of attenuation are then converted to transmissivity for $\mathrm{H}$ and $\mathrm{V}$ polarization through a simple relationship and interpolated to produce a transmissivity value for each day during the growing season. The transmissivity curves are also converted into tau curves for each polarization, and compared to the measured VWC curves to determine whether the VWC variations alone are sufficient to enable accurate soil moisture retrieval throughout the growing season, or whether a non-constant and polarization-dependent $b_{p}$ parameterization is needed for improved soil moisture estimation, and how $b_{p}$ differs in drought and normal years.

\section{REFERENCES}

[1] Entekhabi, D., E, Njoku, P. O’Neill, K. Kellogg, plus 19 others, "The Soil Moisture Active Passive (SMAP) Mission," Proceedings of the IEEE, Vol. 98, No. 5, May, 2010.

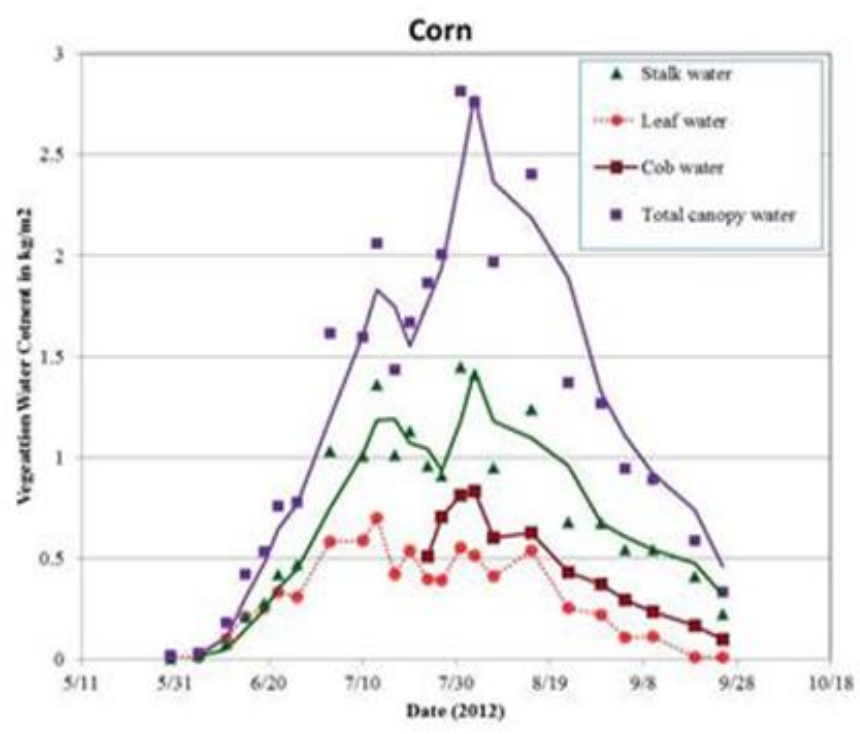

[2] Kerr, Y., P. Waldteufel, P. Richaume, I. Davenport, P. Ferrazoli, and J.-P. Wigneron, SMOS Level 2 Processor Soil Moisture Algorithm Theoretical Basis Document (ATBD), Toulouse, France, CESBIO, SM-ESL (CBSA), vol. SO-TNESL-SM-GS-0001, v5.a, 2006.

[3] O'Neill, P., S, Chan, E. Njoku, T. Jackson, and R. Bindlish, SMAP Level 2 \& 3 Soil Moisture (Passive) Algorithm Theoretical Basis Document (ATBD), Initial Release v.1, JPL D-66480, Jet Propulsion Laboratory, October, 2012.

[4] Jackson, T. J. and T. J. Schmugge, "Vegetation effects on the microwave emission from soils," Rem. Sens. Environ., vol. 36, pp. 203-212, 1991.

[5] USDA web site at http://www.ars.usda.gov/Research/.

[6] O’Neill, P., A. Joseph, G. De Lannoy, R. Lang, C. Utku, E. Kim, P. Houser, and T. Gish, "Soil Moisture Retrieval Through Changing Corn Using Active/Passive Microwave Remote Sensing," Proc. of IGARSS '03, Toulouse, France, July, 2003.

[7] O’Neill, P., M. Kurum, A. Joseph, J. Fuchs, P. Young, M. Cosh, and R. Lang, "L-Band Active / Passive Time Series Measurements over a Growing Season using the ComRAD Ground-Based SMAP Simulator," Proc. of IGARSS'13, IEEE, Melbourne, Australia, July 22-26, 2013.

[8] Chauhan, N., D. Le Vine, and R. Lang, "Discrete scatter model for microwave radar and radiometer response to corn: comparison of theory and data," IEEE Trans. Geos. Rem. Sens., 32, pp. 416-426, 1994.

\section{Corn Canopy Constituent Water Content at OPE 3}

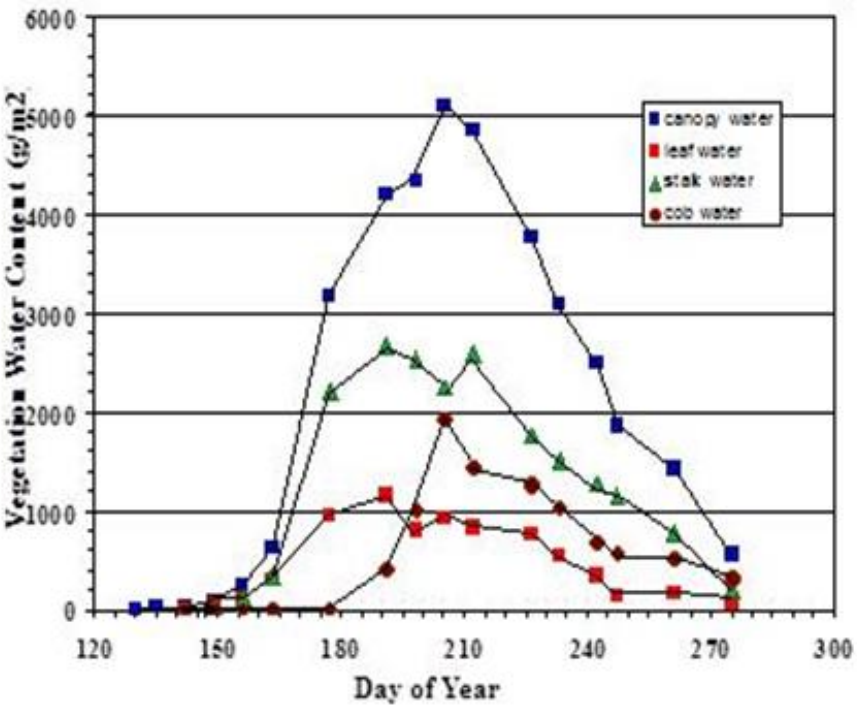

Figure 2. (a) VWC curves (by plant constituent) for corn at the OPE3 test site in 2012; note that peak VWC for the canopy was $<3 \mathrm{~kg} / \mathrm{m}^{2}$; (b) Similar VWC curves for corn at the OPE3 test site in 2002; note the more normal peak VWC for the canopy was $>5 \mathrm{~kg} / \mathrm{m}^{2}$. 